\title{
What language (s) should a Chinese child speak: Mandarin or dialect or both
}

\author{
Qiaoling Wu, Xiaoqiong Hu \\ College of Foreign Languages, China Three Gorges University, Yichang, China
}

Email address:

amber3xia@126.com (Qiaoling Wu), huxiaoqiong@yahoo.cn (Xiaoqiong Hu)

To cite this article:

Qiaoling Wu, Xiaoqiong Hu. What Language (s) Should a Chinese Child Speak: Mandarin or Dialect or Both. International Journal of Language and Linguistics. Vol. 2, No. 4, 2014, pp. 246-251. doi: 10.11648/j.ijl1.20140204.11

\begin{abstract}
Children's language acquisition is usually significantly influenced by their parents' attitude towards a certain language. This paper attempts to investigate Chinese parents' views regarding what language(s) their children should speak: Mandarin, dialect or both, as well as the reasons for their opinions. The research is mainly carried out through questionnaires targeted at Chinese parents of young children. It is shown that parents give different degrees of preference to Mandarin and Chinese dialect which are thus spoken at different frequencies. Mandarin, as the standard form of Chinese, is reckoned as much more useful and as a marker of being better educated, so it is vigorously advocated as the first language children are expected to acquire. It can largely account for why most children of the new generation are not able to speak any Chinese dialect. Even so, more than half of the parents investigated still consider speaking dialect to be essential due to its particular superiority in expressing friendliness and transmitting traditional culture. Based on the research findings, we tentatively conclude that most parents, faced with what language a child should acquire as the first language, generally attach more importance to the function of a certain language. However, both Mandarin and dialect need to be spoken for the sake of maintaining individual identity as well as cultural prosperity.
\end{abstract}

Keywords: Mandarin, Chinese Dialect, Language Attitude, Language Use, Parents, Children

\section{Introduction}

The language use of Chinese children has undergone profound changes compared with that of the past generation. An increasing number of children are found to be able to speak Mandarin (standard Chinese or Putonghua) and also speak it much more often than their local dialect. Many of them even can only speak Mandarin. One important reason lies presumably in the fact that Chinese parents in modern times prefer bringing up children in Mandarin than in Chinese dialect. Consequently, children are not allowed to speak dialect by their parents, or else are frequently discouraged from doing so; at best, they are only permitted to speak it on certain occasions. It is obvious that parents' beliefs in and attitudes towards a language exert great influence on which language (s) their children acquire and use. Why is Mandarin so strongly advocated whereas dialects are strictly restrained when children are growing up? How does parents' language attitude influence the language use of children? In order to find answers to these questions, we distributed questionnaires to Chinese parents of young children in an attempt to obtain a better knowledge of their views regarding what language (s) a Chinese child should speak: Mandarin, dialect or both.

\section{Literature Review}

\subsection{Definition of Language Attitude}

In order to understand what language attitude is, we need, above all, to examine how "attitude" is identified in social psychology. Among the diverse versions, some psychologists defined attitude as consisting of three components, i.e. "cognitive beliefs about a person or object, affective or evaluative feelings about the person or object, and behavior towards that person or object" (Liaquat et al., 2011). Language attitude, accordingly, indicates people's beliefs about language or, to be more precise, "the value evaluation and behavior inclination that people have of one language or dialect" (You Rujie \& Zou Jiayan, 2004: 83). It is implied that the attitude towards language includes how to evaluate a language, such as its social status, functions and prospect, and furthermore reflects the tendency to perform certain actions. Therefore, as a typical social psychological 
phenomenon, a speaker's language attitude will essentially affect which language is chosen by him or her to be the language of communication.

\subsection{Previous Studies}

Since the 1970s, a vast number of studies on language attitude have been carried out both at home and abroad, and many significant results achieved. For most research abroad (Edwards, 1982; Bourhis, 1982; Garcia et al., 1988; Woolard \& Gahng, 1990; Wassink, 1999; etc.), the focus is primarily placed on the differences in people's attitudes towards standard varieties and non-standard varieties as well as the social stratification. However, Day (1982) investigated how parents' attitudes towards a certain language variety affect their children, particularly their language acquisition. He believed that language attitude is an important component of children's developing communicative competence. In China, in contrast, investigations are mainly conducted with respect to people's attitudes towards Mandarin and dialects (Sha Ping, 1988; Liu Hong, 1993; Zhou Wei, 2011), minority languages (Wang Yuanxin, 1999; Dao Bu, 2005), Chinese and foreign languages (Chen Songcen, 1999; Ni Chuanbin et al., 2004).

China is typically characterized by the universal phenomenon of bi- and multilingualism. People in many provinces and regions of China are frequently found to be able to speak Mandarin as well as one or more kinds of Chinese dialect. With the implementation of the policy of promoting Mandarin in China, according to Liu Hong (1993), it is of vital importance to investigate how people's language attitudes restrict the learning and using of standard language, and how they influence the evolution of dialects in some regions where the standard variety and local dialects coexist.

It must be noted that the previous studies, however, are mainly concerned with people's attitudes towards a certain language as well as how their attitudes, in turn, affect people's language use. Moreover, as is pointed out by Zhao Yan (2009:76), "the research is generally concentrated in dialects in a limited number of provinces and areas including Jiangsu, Shanghai, Guangdong, etc." Taking all these elements into account, we carried out an investigation in Yichang, Hubei province, a medium-sized city in central China, in an attempt to know about the young parents' attitude towards Mandarin and dialect, as well as what influence their attitude exerts on the language acquisition and use of their children in the course of growing up.

\section{Research Methodology}

\subsection{Research Questions}

1. What are parents' opinions about whether a Chinese child must be able to speak Mandarin and dialect? What are the reasons for their opinions?

2. How does parents' attitude towards language influence a child's language acquisition?

\subsection{Method}

In this investigation, we employed a quantitative study which was carried out using questionnaires. Based on the research questions mentioned above, the questionnaire consists of altogether 10 questions with regard to children's ability to speak Mandarin and dialect, parents' attitude towards what language their children should acquire, and the underlying reasons for their opinions. Since the investigation was mainly targeted at Chinese parents, the questionnaire was written in Chinese. The questions involved were almost all presented in the form of multiple choices. Parents were also invited to supplement their answers if they were not previously given in the options. In this way, we could expect to collect more comprehensive and valid information.

\subsection{Participants}

Participants selected to do the questionnaire were restricted to the parents whose children are aged from 3 to 12 That is to say, they are still pupils in either kindergarten or primary school. The opinions of these parents can presumably represent those of their peers, so to speak, parents of the new generation. 20 questionnaires were altogether distributed to 20 pairs of parents. They were invited to finish the questionnaire based on their real situation and to say what they really thought. The questionnaires were taken back soon afterwards. Finally all the 20 questionnaires were collected and proved to be valid for further data analysis.

\subsection{Results and Analysis}

Table 1. Questionnaire results regarding children's ability to speak dialect

\begin{tabular}{|c|c|c|c|}
\hline Questions 1-3 & Options & Number of parents & Percentage \\
\hline \multirow{3}{*}{$\begin{array}{l}\text { Q.1 Is your child able to } \\
\text { speak any Chinese dialect? }\end{array}$} & Yes. & 4 & $20 \%$ \\
\hline & No. & 16 & $80 \%$ \\
\hline & Parents are unable to speak dialect. & 0 & $0 \%$ \\
\hline \multirow{3}{*}{$\begin{array}{l}\text { Q. } 2 \text { If no, what are the } \\
\text { reasons? }\end{array}$} & Parents are able to speak dialect but never speak it to the child. & 8 & $50 \%$ \\
\hline & Parents seldom speak to the child. & 8 & $50 \%$ \\
\hline & $\begin{array}{l}\text { Though parents often speak dialect to the child, the child insists on } \\
\text { speaking Mandarin. }\end{array}$ & 0 & $0 \%$ \\
\hline \multirow{4}{*}{$\begin{array}{l}\text { Q.3 If yes, do you permit } \\
\text { or encourage your child to } \\
\text { speak dialect? }\end{array}$} & Permit and encourage. & 1 & $25 \%$ \\
\hline & Permit but not encourage. & 3 & $75 \%$ \\
\hline & Do not permit. & 0 & $0 \%$ \\
\hline & I don't care. & 0 & $0 \%$ \\
\hline
\end{tabular}


The first three questions concern whether their children are able to speak any dialect or not, the reasons for that if they are not able to do so and whether parents permit or encourage them to speak dialect if they are. The results are shown in Table 1.

Among the 20 parents investigated, $80 \%$ said that their children are not able to speak any dialect whereas only $20 \%$ claimed their children are able to do so. With regard to the reasons for children's inability to speak any dialect, half of the 16 parents never speak dialect to their children even though they themselves are able to; the other half just occasionally or seldom talk with their children in dialect. None chose the answers "Parents and family members are unable to speak dialect"; "Though parents often speak dialect to the child, the child insists on speaking Mandarin". It can be inferred that the vast majority of children today are not able to speak any Chinese dialect. This phenomenon, however, is largely due to the fact that many parents never or seldom speak dialect to their children. In consequence, children are severely deprived of the chances to be exposed to a natural dialect-speaking environment. A lack of exposure will definitely and directly impede a child's acquisition of dialect.

Regarding the four parents whose children are able to speak dialect, their opinions on the question "whether their children are permitted or encouraged to speak dialect" show subtle differences. Only one permits as well as encourages his/her child to speak dialect. The remaining three permit but don't encourage their children to speak dialect. None of them said $\mathrm{s} /$ he doesn't permit the child to speak dialect if the child is able to. No one held that $\mathrm{s} /$ he doesn't care about whether his/her child speaks dialect. It is demonstrated that as long as a child is able to speak dialect, $\mathrm{s} /$ he is generally permitted by the parents to speak it. However, it must be pointed out that most children are still not encouraged to speak dialect too often. In other words, Mandarin is endowed, on the parents' part, with significantly greater preference than any Chinese dialect concerning which language is expected to be employed by children for daily use.

Table 2. Questionnaire results regarding where and when children are permitted to speak dialect or the reason why they are not

\begin{tabular}{|c|c|c|c|}
\hline Questions 4-5 & Options & Number of parents & Percentage \\
\hline \multirow{4}{*}{$\begin{array}{l}\text { Q.4 If you permit your child } \\
\text { to speak dialect, on what } \\
\text { occasions? (You may choose } \\
\text { more than one answer.) }\end{array}$} & With family members. & 3 & $100 \%$ \\
\hline & With classmates and friends. & 2 & $70 \%$ \\
\hline & At school. & 0 & $0 \%$ \\
\hline & On any occasion outside school. & 0 & $0 \%$ \\
\hline \multirow{5}{*}{$\begin{array}{l}\text { Q. } 5 \text { If you don't permit } \\
\text { them to do so, what are the } \\
\text { reasons? (You may choose } \\
\text { more than one answer.) }\end{array}$} & There is no good speaking dialect. & 0 & $0 \%$ \\
\hline & $\begin{array}{l}\text { Speaking dialect does harm to the development of a child's } \\
\text { language ability. }\end{array}$ & 1 & $100 \%$ \\
\hline & Speaking dialect doesn't conform to the student image. & 0 & $0 \%$ \\
\hline & Children are required to speak Mandarin at school. & 1 & $100 \%$ \\
\hline & Other reasons. & 1 & $100 \%$ \\
\hline
\end{tabular}

With respect to the three parents who permit their children to speak dialect, they all permit their children to use it when staying with family members. In addition, $70 \%$ of them also allow their children to speak dialect to classmates and friends. None will allow their children to speak dialect at school or agree that children are free to speak dialect on any occasions outside school. The results reveal that dialect is frequently used among acquaintances that know each other very well and stay in close relationship. Moreover, people are generally inclined to speak dialect more often on informal occasions than in formal settings like at school and so on.
There is only one parent arguing that s/he doesn't permit the child to speak dialect for the following two reasons. First, speaking dialect may exert a bad influence on the development of a child's language ability. It corresponds to the detailed reason $\mathrm{s} /$ he supplemented, i.e. speaking dialect will in all probability interfere in a child's acquisition of standard Mandarin pronunciation. Second, speaking Mandarin is what is vigorously advocated and required at school. So the parent doesn't permit his or her child to speak dialect in order to show favor and cooperation with the school for the benefit of the child's Mandarin acquisition.

Table 3. Questionnaire results regarding parents' attitude towards speaking Mandarin and the reasons

\begin{tabular}{|c|c|c|c|}
\hline Questions 6-7 & Options & Number of parents & Percentage \\
\hline \multirow{2}{*}{$\begin{array}{l}\text { Q.6 Do you think children today } \\
\text { must be able to speak Mandarin? }\end{array}$} & Yes, they must. & 20 & $100 \%$ \\
\hline & No, not necessarily. & 0 & $0 \%$ \\
\hline \multirow{4}{*}{$\begin{array}{l}\text { Q. } 7 \text { If yes, what are the main } \\
\text { reasons? } \\
\text { (You may choose more than one } \\
\text { answer.) }\end{array}$} & In response to the national call for popularizing Mandarin. & 8 & $40 \%$ \\
\hline & Speaking Mandarin is an essential quality for people today. & 14 & $70 \%$ \\
\hline & To facilitate communication with others (especially outsiders). & 18 & $90 \%$ \\
\hline & $\begin{array}{l}\text { Speaking Mandarin benefits children's future career and personal } \\
\text { development }\end{array}$ & 16 & $80 \%$ \\
\hline
\end{tabular}


As is shown in Table 3, all the 20 parents investigated, without exception, agreed that children nowadays must be able to speak Mandarin. In other words, Mandarin is unanimously considered as a compulsory language for children today. However, diversely different reasons were given by different parents. $40 \%$ of them consider speaking Mandarin to be necessary on account of the national calls for popularizing Mandarin. $90 \%$ contend that speaking Mandarin can facilitate interpersonal communication, particularly with outsiders. $70 \%$ of parents, however, regard speaking Mandarin as a necessity for people today. $80 \%$ of them also maintain that if a child is able to speak Mandarin, it will be of great benefit for his or her job hunting and personal development in the future.

It can be thus presumed that parents in modern times have been fully aware of the importance of learning to speak Mandarin. Accordingly, almost all the children are expected to acquire Mandarin. As for those parents who are able to speak Mandarin themselves, they would choose to bring up their children in Mandarin from the infant stage. In addition, some courses concerning Mandarin are offered in kindergartens and primary schools. Pupils are often only allowed to talk with teachers and classmates in Mandarin. With so many measures taken, children are thereby, to some extent, positioned in a Mandarin-speaking environment, in which they can both learn and acquire Mandarin.

Table 4. Questionnaire results regarding reasons for speaking or not speaking dialect

\begin{tabular}{|c|c|c|c|}
\hline Questions 8-10 & Options & Number of parents & Percentage \\
\hline Q.8 Do you think it is & Yes. & 12 & $60 \%$ \\
\hline necessary for children today & No. & 6 & $30 \%$ \\
\hline to speak dialect? & I don't care. & 2 & $10 \%$ \\
\hline \multirow{4}{*}{$\begin{array}{l}\text { Q. } 9 \text { If yes, what are the } \\
\text { reasons? (You may choose } \\
\text { more than one answer.) }\end{array}$} & Dialect sounds sweet and kind and it is good for expressing emotions. & 10 & $83 \%$ \\
\hline & Dialect marks one's own identity. & 4 & $33 \%$ \\
\hline & Learning one more language helps to develop a child's intelligence. & 1 & $8 \%$ \\
\hline & Speaking dialect helps pass down and sustain local culture. & 12 & $100 \%$ \\
\hline \multirow{4}{*}{$\begin{array}{l}\text { Q. } 10 \text { If no, what are the } \\
\text { reasons? }\end{array}$} & Dialect is the language of those who have a low level of literacy. & 0 & $0 \%$ \\
\hline & Dialect bears no authority. & 2 & $33 \%$ \\
\hline & $\begin{array}{l}\text { Dialect is of no practical use for communication between people from } \\
\text { different areas. }\end{array}$ & 6 & $100 \%$ \\
\hline & Dialect is non-standard and hard to learn. & 5 & $83 \%$ \\
\hline
\end{tabular}

According to the statistics in Table 4, different parents have different attitudes towards whether it is necessary for children to be able to speak dialect. It is in sharp contrast with their attitudes towards Mandarin. To be specific, more than half, i.e. $65 \%$ of them believe speaking dialect is necessary; $35 \%$ of them, however, do not think of speaking dialect as essential for children today. When the reasons why speaking dialect is necessary are investigated, all the 13 parents involved believe that speaking dialect is to the benefit of passing down and sustaining the traditional culture of the speakers' hometown. $77 \%$ maintain that dialect sounds sweet and kind so that it is more suitable to be used to express our feelings and emotions. In contrast, only $31 \%$ of them regard dialect as one marker of people's identity. Even less people, i.e. 8\% admit that learning different kinds of languages or language varieties is conducive to the development of a child's intelligence.

We can deduce from the results that dialect is favorably advocated by most young parents. They by and large accept dialects as part of our ethnic culture. In fact, some people are even supportive of their own dialects and accents. Even though dialects might have a limited range of use in real life, it is considered a fundamental component of one's ethnic identity. Just as Fishman (1991: 341) argued: “All dialects reveal where one's childhood home is or was, i.e. all dialects are not only informality markers but also regional markers or social class markers." Indeed when we are speaking dialects, we generally feel more at ease and sound much sweeter to each other.

\subsection{Discussion}

As one kind of social psychological phenomenon, language attitude is constantly evolving along with the development of the times. In the contemporary language situation in China, according to Fu Yirong (2011: 83), the rapid popularization of Mandarin and the sharp shrinkage of Chinese dialects account for the two most prominent features. However, why is Mandarin increasingly valued in the modern society? Tu Guoping (2009: 62) claimed that "language acquisition and language learning can be ascribed to the practicality of language...the more useful a language is in real life, the stronger initiative people will take in learning it". Therefore, the huge practical value of Mandarin accounts for its wide recognition throughout the country.

As is shown in the research results, parents who insist on bringing up children in Mandarin attach much importance to its communicative value. It goes beyond doubt that Mandarin outweighs any dialect in many respects. For instance, speaking Mandarin can efficiently eliminate unintelligibility that frequently occurs when people from different dialect areas communicate with each other. Having both the spoken and written form, Mandarin is overtly admired and generally identified as the "standard variety" in China, which is assumed to have an enormous legacy of overt prestige. Governments, schools, companies and many institutions are inclined to employ this language variety as the working language in order to manifest and, in turn, to enhance formality and authoritativeness. Therefore, the 
ability to speak Mandarin, in many parents' view, proves to be one basic requirement for children's future career.

According to Holmes (1992: 344), the attitude to a language reflects the attitude to its users. In other words, our speech can not only express the feelings and ideas, but also convey speakers' public image and social identity. So, in Chinese context, people who speak the standard variety or "good speech" (Mandarin), are often rated highly on scales of educational and occupational status. Correspondingly, people generally adhere to the stereotype that a low level of education and inferior job status are supposedly associated with those dialect speakers. Besides, many hold that children will in all probability fail to acquire the pure and authentic "standard language" from the very beginning if they are brought up on dialects, whose pronunciation differs significantly from that of the standard variety. Presumably, those stereotyped perceptions of Chinese dialects apparently weigh against their survival and conservation in the long term. The reasons why people condemn dialects are attitudinal, not linguistic. "Indeed, almost all children everywhere in the world start out as dialect speakers" (Fishman, 1991: 340). Children who use vernacular forms are disadvantaged by negative attitudes towards their speech which derive from their lower social status and its associations in people's minds.

However, as far as the function is concerned, Mandarin and dialect are mutually complementary (Jin Song, 2009: 274). Mandarin is, of course, exclusively favored on formal occasions whereas dialect is still used with great vitality in casual settings. When two ordinary people talk with each other, dialect is often preferred in order to show they are on intimate terms. In other words, dialectal accent generally gains higher ratings on solidarity related features such as sincerity, friendliness, reliability and sense of humor. People who tend to speak dialect may gain a sense of belonging.

There is not such a distinction of noble quality and low ranking between Mandarin and local dialects, since each language or language variety represents as well as reflects a particular culture. Even though Mandarin is vigorously promoted nationwide, its impetus lies in bridging the gap between different regional dialects, not inhibiting or even eliminating the use of dialects. Dialects will never be replaced by Mandarin. Instead, the two will coexist and develop in the long-term since they are playing an important role in their respective fields.

\section{Conclusion}

The issue of what language(s) a Chinese child should speak is very much related to people's language attitude which is "embodied in language evaluation, language ability, language use and language inclination" (Tu Guoping, 2009: 56). The research shows Mandarin and Chinese dialect receive different degrees of preference and are spoken at different frequencies. The former, in the view of most parents, is superior and of more practical use, and thus favorably advocated as the first language children are expected to acquire. Even so, many parents still consider speaking dialect to be essential on account of its particular role in expressing friendliness and transmitting traditional culture. Based on the research findings, we tentatively conclude that parents, faced with what language(s) a child is supposed to acquire as the first language, generally attach much importance to the function of a certain language. However, different language varieties serve different functions and need survive for good reasons. Therefore, it is advisable for Chinese children not to be demotivated to speak dialect or deprived of the natural environment to acquire it. Instead, both Mandarin and dialect need to be spoken for the sake of maintaining individual identity as well as cultural prosperity. After all, the use of a language is what maintains the vitality of the language (Chen Songcen, 1999: 92).

\section{References}

[1] Bouthis, R. Y. (1982). Language Policies and language attitudes: Le monde de la Francophonie, In Carranza, M. A., (1982), Attitudinal research on Hispanic language varieties, In E. B. Ryan \& H. Giles (eds.), Attitudes Towards Language Variation. London: Edward Arnold.

[2] Chen Songcen. (1999). Chinese Singaporeans' language attitude and its influence on language competence and language use. Language Teaching and Linguistics Studies.

[3] Dao Bu. (2005). The Language Vigor, Language Attitude and Language Policy. Academic Exploration. 6.

[4] Day, R. R. (1982). Children's attitudes towards language. In E. B. Ryan \& H. Giles (eds.), Attitudes Towards Language Variation. London: Edward Arnold.

[5] Edwards, J. R. (1982). Language attitudes and their implications among English speakers. In E. B. Ryan \& H. Giles (eds.), Attitudes Towards Language Variation. London: Edward Arnold.

[6] Fishman, J. A. (1991). Reversing Language Shift: Theoretical and empirical foundations of assistance to threatened languages. Clevedon: Multilingual Matters.

[7] Fu Yirong. (2011). A Study on Speech Community and Language Change. Beijing: Peking University Press.

[8] Garcia, Ofelia, Isabel Evangelista, Mabel Martinez, Carmen Disla \& Bonifacio Paulino. (1988). Spanish language use and attitudes: a study of two New York City communities. Language in Society. 17: 475- 511.

[9] Holmes, J. (1992). An Introduction to Sociolinguistics. London: Longman.

[10] Jin Song. (2009). Sociolinguistics. Beijing: The Ethnic Publishing House.

[11] Liaquat, Hussain, Dr Asif Jamil, Allah Noor, Muhammad Sibtain \& Syed Muhammad Ali Shah. (2011). Relationship between the Professional Attitudes of Secondary School Teachers with Their Teaching Behavior. International Journal of Academic Research in Business and Social Sciences. 1: 38-46.

[12] Liu Hong. (1993). Influences of Language attitude on language use and language change. Applied Linguistics. 
[13] Ni Chuanbin, Wang Zhigang, Wang Jiping \& Jiang Meng. (2004). A Survey on the Language Attitude towards Chinese among International Students. Language Teaching and Research. 4.

[14] Sha Ping. (1988). Application of Matched-guise Technique Method. Language Planning. 3.

[15] Tu Guoping. (2009). Language Attitude of Native and Non-Native Residents in Ningbo City. The Journal of Chinese Sociolinguistics. 1

[16] Wang Yuanxin. (1999). On the Language Attitude of Yugur. Language and Translation. 2.

[17] Wassink, A. B. (1999). Historic low prestige and seeds of change: Attitudes towards Jamaican Creole. Language in Society. 28:57-92.
[18] Woolard, K. A. \& Gahng, T. J. (1990). Changing language policies and attitudes in autonomous Catalonia. Language in Society. 19: 311-330.

[19] You Rujie \& Zou Jiayan. (2004). Sociolinguistics. Shanghai: Fudan University Press.

[20] Zhao Yan. (2009). A Summary of the Past Twenty-year Studies on Language Attitudes. Journal of Yunnan Normal University (Teaching and Research on Chinese as a Foreign Language Edition). 5.

[21] Zhou Wei. (2011). The Relationship between Language Attitudes and Language Uses: Taking 2007's Nanjing Urban Language Survey for Example. Language Teaching and Research. 1. 